\title{
Relationship between the Onset of the South China Sea Summer Monsoon and the Structure of the Asian Subtropical Anticyclone
}

\author{
Jiangyu MAOํ, Johnny C.L. CHAN \\ Laboratory for Atmospheric Research, Department of Physics and Materials Science, \\ City University of Hong Kong, China \\ and \\ Guoxiong WU \\ LASG, Institute of Atmospheric Sciences, CAS, Beijing, China
}

(Manuscript received 23 July 2003, in final form 16 December 2003)

\begin{abstract}
The US National Centers for Environmental Prediction/National Center for Atmospheric Research (NCEP/NCAR) reanalysis data are employed to study the relationship between the variation in the structure of subtropical anticyclone and the summer monsoon onset over the South China Sea (SCS). The ridge surface of the subtropical anticyclone is defined by the boundary between westerly to the north and easterly to the south [or westerly-easterly boundary (WEB) in brief]. The WEB well represents the three-dimensional structure of the subtropical anticyclone. Under the thermal wind constraint, the WEB usually tilts toward the warmer zone in the vertical. In the Asian monsoon area, the ridgelines of the subtropical anticyclone at various levels in the troposphere in winter are continuous and exhibit a relatively zonal structure. The WEB tilts southward with increasing height and the mean position of the WEB is closer to the equator. In summer, the ridgelines of the subtropical anticyclone in the middle and lower (upper) troposphere are discontinuous (continuous) and the WEB either tilts northward or is vertical, with the mean position of the WEB being located at $25-30^{\circ} \mathrm{N}$. May is the period when the structure of the subtropical anticyclone varies most significantly.

During the seasonal transition, the tilt of the WEB changes from southward to northward. When the WEB becomes perpendicular to the earth's surface or tilts northward, the meridional temperature gradient vanishes or becomes positive, implying the replacement of the winter monsoon by the summer monsoon. Defining the "seasonal transition axis" (STA) as the vertical ridge axis that results from the switching of the tilt of the WEB from southward to northward, it is found that the STA first establishes over the eastern Bay of Bengal and Indochina Peninsula during the first pentad of May. The onset of the Asian summer monsoon circulation is therefore closely associated with the location of the STA. When the STA reaches the northeastern SCS in the fourth pentad of May, the SCS summer monsoon occurs. The south Asian summer monsoon onset corresponds to the establishment of the STA over central India in the first two pentads of June. Based on the close relationship between the STA and monsoon onset,
\end{abstract}

Corresponding author: Johnny Chan, Dept. of Physics and Materials Science, City University of Hong Kong, 83 Tat Chee Ave., Kowloon, Hong Kong, China.

E-mail: Johnny.Chan@cityu.edu.hk

1 Permanent affiliation: LASG, Institute of Atmospheric Sciences, CAS, Beijing, China.

(C) 2004, Meteorological Society of Japan 
the area-averaged meridional mean upper tropospheric (200-500 hPa) temperature gradient in the vicinity of the WEB is suggested to be an index to define the SCS summer monsoon onset. In comparison with the onset dates as determined by the area-averaged zonal wind at $850 \mathrm{hPa}$ and OLR, the dates determined by these three indices are consistent in a large number of individual years, which indicates that the establishment of the STA, or the reversal of the meridional temperature gradient, captures the essential feature associated with the SCS summer monsoon onset.

\section{Introduction}

The onset of the Asian summer monsoon indicates the beginning of the rainy season. Small variations in the timing and quantity of rainfall have the potential for significant societal consequences (Webster et al. 1998). An important component of East Asian summer monsoon is the summer monsoon over the South China Sea (SCS), which He et al. (2001) considered to be the connecting gear that links the East Asian monsoon and South Asian monsoon systems. The onset of the SCS summer monsoon (SCSSM) is signified by a large-scale wind shift in the lower troposphere from easterly to westerly, and an outburst of deep convection over the SCS (Lau et al. 1998; Ding and Li 1999; Chan et al. 2000; Lau et al. 2002). Climatologically, the onset of the SCSSM is around mid-May (Tao and Chen 1987; Chang and Chen 1995; Lau and Yang 1997; Hsu et al. 1999). Disagreements exist as to whether the earliest onset of the Asian summer monsoon occurs over the SCS. Wu and Zhang (1998) pointed out that the Asian summer monsoon onset consists of three consequential stages, firstly over the eastern Bay of Bengal (BOB), then the SCS, and lastly South Asia. Fong and Wang (2001) supported this idea based on their analyses of the climate mean $850-\mathrm{hPa}$ winds. In fact, the climatological onset date of the Asian summer monsoon found by Lau and Yang (1997) and Webster et al. (1998) also did not indicate that the SCSSM first occurs in the Asian summer monsoon regime. The onset date of the SCSSM in a particular year can also differ among different researchers (e.g., Dai et al. 2000; He et al. 2001). Such discrepancies suggest that the onset characteristics associated with the SCSSM, as well as the evolution of the entire Asian summer monsoon, need to be further explored.

The South China Sea Monsoon Experiment (SCSMEX), carried out in 1998 over the SCS, provides good opportunities to study the physical processes for the SCS monsoon activities. Based on the observational datasets available during SCSMEX, many researchers have examined the 1998 SCSSM onset and considered that it occurred around 20-25 May (Chan et al. 2000; Ding and Liu 2001; Xu and Chan 2001; Lau et al. 2002; Liu et al. 2002). Unfortunately, such comprehensive data are not available every year for studying the climatological features associated with the SCSSM onset. Composite studies are therefore necessary.

The monsoon is not only a seasonal shift of wind direction, but also a seasonal change in pressure distribution over the tropics, subtropics and the associated midlatitude regions. Previous studies have emphasized the impacts of the subtropical high on the monsoon. For example, Tao and Chen (1987) reported that the Western Pacific subtropical high (WPSH) and the South Asian high (SAH) are important components of the East Asian monsoon system. The meridional shift of the WPSH ridge and its zonal migration influence the location where its southeasterlies converge with the southwesterlies from the Somali cross-equatorial flow, and hence the convection associated with the summer monsoon. In recent years, deep convective condensation heating related to the summer monsoon has also been shown to contribute to the formation and variation of the subtropical anticyclone (Hoskins 1996; Liu et al. 2001; Rodwell and Hoskins 2001). Therefore, an interactive relationship apparently exists between the summer monsoon and the subtropical high.

The basic driving force of most of the monsoons is the differential heating between land and ocean, and the resulting pressure gradient force between the summer and the winter hemispheres (Webster et al. 1998). Since the onset of the summer monsoon occurs during a transition season from cool and dry to warm 
and moist conditions, in addition to the lower tropospheric wind fields, it is inevitably related to the changes in temperature, pressure, and wind fields in the entire troposphere through geostrophic and hydrostatic balance constraints. The subtropical anticyclone belt that connects the tropical and midlatitude atmospheric circulation therefore represents a key feature in the Asian monsoon system. Li and Zeng (2000) suggested that the significant seasonality is closely related to the subtropical high, with its ridgeline in January and July being approximately coincident with regions having a significant seasonality. Mao et al. (2002) found that the westerly-easterly boundary surface (WEB) well represents the threedimensional structure of the subtropical anticyclone belt based on theoretical and data analyses. The WEB represents the maximum in the geopotential height (pressure), and is the vertical shear zone between easterlies and westerlies. It can therefore be used as a proxy for the essential features of both the pressure and wind fields. Since the vertical wind shear depends on the meridional temperature gradient (MTG), variations in the configuration of the WEB can also reflect those in the temperature field. These results imply that the WEB may be a good indicator of the seasonal variation of the monsoon. In other words, using the WEB to study the onset and evolution of the Asian summer monsoon provides a threedimensional visualization of the essential features associated with the Asian summer monsoon, as compared with simple fields like rainfall or winds in the lower troposphere that consider only two-dimensional aspects of the monsoon.

$\mathrm{Li}$ and Yanai (1996) found that the Asian summer monsoon onset is concurrent with the reversal of the MTG in the upper troposphere south of the Tibetan Plateau. However, the Asian summer monsoon does not establish simultaneously over different parts of Asia. In which latitudinal extent and which layers is the MTG capable of indicating the monsoon onset for a particular region? A detailed analysis of the relation between the MTG and the WEB would provide information as to which levels and what domain should be used to define the monsoon onset. Such information would lead to a better understanding of the similarities, dif- ferences and linkages among the different parts of Asia during the summer monsoon onset.

In this paper, the subtropical anticyclone belt in the entire troposphere is considered as an integrated entity from the WEB perspective and used to correlate with the climatological features of the Asian summer monsoon onset. A corollary objective is to clarify the controversy about whether the SCSSM onset is the earliest over Asia in the climate mean. Theoretically, variations in the meridional temperature gradient in the vicinity of the WEB due to land-sea thermal contrast can result in the break and switching of the tilt of the WEB. The approach here is therefore to examine the associations between such a switch of the WEB and the wind shift from easterly to westerly at lower levels as well as rainfall based on composites of data from many years.

Section 2 describes the data used and presents a theoretical analysis of the WEB. The break and switch of the WEB tilt and their associations with the Asian summer monsoon onset are examined in sections 3 and 4 respectively. These results are then used to relate to the SCSSM onset date in Section 5. A summary and discussion are given in section 6 .

\section{Data and theoretical discussion of the WEB}

\subsection{Data}

The data used in this study are the monthly and daily mean global National Centers for Environmental Prediction/National Center for Atmospheric Research (NCEP/NCAR) reanalysis data products (Kalnay et al. 1996), which include the wind, geopotential height, temperature, vertical motion, and specific humidity at 17 standard pressure levels with a horizontal resolution of $2.5^{\circ}$ latitude $\times 2.5^{\circ}$ longitude grid from 1958 to 2001 . Pentad means are then constructed from the daily means. The long-term mean is based on the period 1968-1996; this climatological time period is used to avoid some of the problems before $1968^{1}$.

Also employed are the monthly and daily mean NOAA outgoing longwave radiation $(\mathrm{OLR})$ data on a $2.5^{\circ}$ latitude $\times 2.5^{\circ}$ longitude

1 See discussion at http://www.cdc.noaa.gov/ 
grid spanning from June 1974 to December 2001 (except for eight months in 1978). Daily mean climatology covers 1979-1995 (no leap days used in calculations).

\subsection{Relationship between the tilt of the WEB} and the horizontal temperature gradient

The geostrophic wind relationship can be written as

$$
u=-\frac{1}{f} \frac{\partial \Phi}{\partial y},
$$

where $u$ is the geostrophic zonal wind component, $f$ the Coriolis parameter, and $\Phi$ the geopotential height. Both theoretical analyses and data diagnoses indicate that for planetary-scale and large-scale atmospheric motions the geostrophic wind relation is largely valid at latitudes 5 degrees or more away from the equator (e.g., Li and Chou 1998; Mao 2001).

Consider the subtropical zone in the Northern Hemisphere. Along the line $u=0$ and according to (1), $\Phi$ has its extreme value in the $y$ direction. Whether the extreme value is a maximum or minimum then depends on the second derivative of $\Phi$. In the vicinity of the subtropical ridge, $\partial u / \partial y>0$, and hence $\Phi$ reaches its maximum.

That is, the $u=0$ line is also the ridgeline of the subtropical high. In this paper, the ridgeline of the subtropical anticyclone belt is therefore defined by the isotach of zonal wind $u=0$ between westerly to the north and easterly to the south. Consequently, connecting the ridgelines on isobaric surfaces constitute a westerlyeasterly boundary surface, which will be called WEB.

The thermal wind relationship

$$
\frac{\partial u}{\partial p}=\frac{R}{f p}\left(\frac{\partial T}{\partial y}\right)_{p},
$$

suggests a relationship between the tilt of the WEB and the horizontal temperature gradient, where $p$ is the pressure, $T$ the temperature and $R$ the gas constant. In the boreal winter, the tropospheric temperature decreases from the equator to the polar region. According to (2), since the meridional temperature gradient in the vicinity of the WEB is negative $(\partial T / \partial y<0)$, $\partial u / \partial p<0$. Thus the WEB tilts southward with increasing height (Fig. 1a). In the boreal summer, the ridgelines of the subtropical anti- (a)

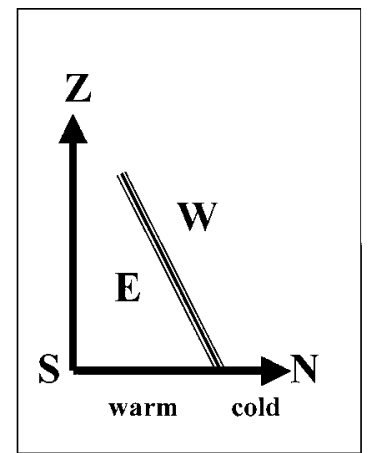

Winter Type (b)

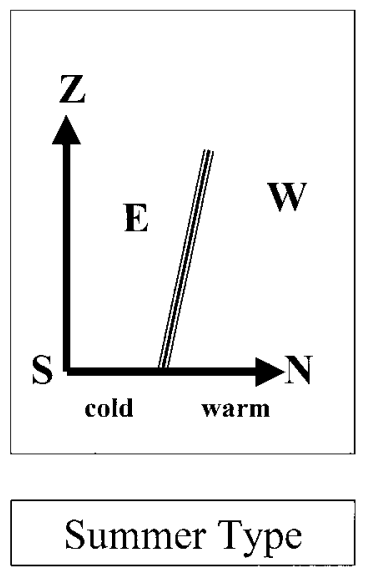

Fig. 1. Schematic diagram showing the tilt of the WEB with height in boreal (a) winter and (b) summer. The triple line denotes the WEB surface. E and W are easterly and westerly winds. Adapted from Mao (2001).

cyclone in the lower troposphere are broken, and the WEB in the middle-upper troposphere has a northward tilt over the Afro-Asian monsoon area because the air temperature over the subtropical continent is higher than that over the Indian Ocean on the same isobaric surface (Fig. 1b). When the meridional temperature gradient equals zero, the WEB is perpendicular to the earth's surface.

The above analyses suggest that for largescale atmospheric motions, the WEB always tilts toward the warmer region in the vertical when the geostrophic relation is valid, and the tilt is constrained by the thermal wind relation. Therefore, the variation in the configuration of the subtropical anticyclone and in the thermal structure during seasonal transitions can be examined based on the change in the tilt of the WEB.

\section{WEB configuration and the Asian summer monsoon onset}

This section attempts to reveal the climatological features of the broad-scale monsoon circulation based on the WEB using monthly and pentad data, focusing on the boreal spring and early summer transitions. 


\subsection{Temporal and spatial evolutions of the WEB}

To identify the relationship between the break of the WEB and the Asian summer monsoon onset during the seasonal transition, the temporal and spatial structures of the WEB are first examined. In January (Fig. 2a), all ridgelines are continuous curves from $850 \mathrm{hPa}$ to $200 \mathrm{hPa}$, and the ridgelines and the WEB tilt southward with increasing height.

In July (Fig. 2d), the ridgelines in the mid and upper troposphere are located at around $25-30^{\circ} \mathrm{N}$. The WEB keeps a southward tilt east of $148^{\circ} \mathrm{E}$ (indicated by solid triangle) and west of $22^{\circ} \mathrm{E}$ (indicated by solid diamond), indicating that the basic thermal state of the atmosphere near the WEB is still warmer on the south side in these areas. However, the WEB tilts northward or is near vertical over the Afro-Asian monsoon area. The northward tilt is relatively more significant over the eastern parts of China. It is in this region that the western $\mathrm{Pa}$ cific subtropical anticyclone in the mid troposphere ties in with the south Asian high in the upper troposphere. Note also that the ridgelines below $400 \mathrm{hPa}$ are discontinuous.

In April (Fig. 2b), the subtropical anticyclone belt basically keeps the winter structure with a generally southward tilt. However, between $60^{\circ} \mathrm{E}$ (point B) and $110^{\circ} \mathrm{E}$ (point A), the $850-\mathrm{hPa}$ ridgeline moves to south of that at $700 \mathrm{hPa}$, which suggests that the tilt of the WEB in the lower troposphere within these longitudes is the first to change. In other words, based on (2), the mean MTG between 850 and $700 \mathrm{hPa}$ has reversed along $10-20^{\circ} \mathrm{N}$, and within $60-110^{\circ} \mathrm{E}$. Note also that between $95^{\circ} \mathrm{E}$ and $105^{\circ} \mathrm{E}$ the ridgeline at $850 \mathrm{hPa}$ even reaches south of that at $500 \mathrm{hPa}$.

In May (Fig. 2c), two essential changes occur in the structure of the subtropical anticyclone belt. One is the north-south tilt of the WEB, and the other the west-east discontinuity. It can be seen that the ridgelines below $400 \mathrm{hPa}$ are all broken over the $\mathrm{BOB}$, and the ridgelines at all levels $(850-200 \mathrm{hPa})$ stack up at $115^{\circ} \mathrm{E}$ (point C). East of this point and west of $55^{\circ} \mathrm{E}$ (point B), the subtropical anticyclone configuration remains as the winter type. Between $90^{\circ} \mathrm{E}$ and $115^{\circ} \mathrm{E}$, the WEB tilts northward, which is the typical summertime structure. Note that the tilt is larger than that in July. Mao et al. (2002) refer to the point C, where the ridge axis is vertical, as the "seasonal transition axis" (STA). It is obvious that these features are closely related to the Asian summer monsoon onset over the BOB and the SCS.

The structure of the subtropical high over South Asia within the longitudes $70-90^{\circ} \mathrm{E}$ is more complicated. The WEB over central India between 700 and $300 \mathrm{hPa}$ tilts southward, but that above $300 \mathrm{hPa}$ tilts northward instead. This suggests a warm center in the middle troposphere over south India $\left(5-13^{\circ} \mathrm{N}\right)$. A "discontinuity" of the WEB also appears in the mid troposphere near $90^{\circ} \mathrm{E}$. The split of the ridgelines at 500 and $400 \mathrm{hPa}$ resemble that over the central North Pacific, where the mid-Pacific trough cuts off the subtropical anticyclone belt (Li and Chou 1998). The northward propagation of the ridgelines at 200 and $300 \mathrm{hPa}$ from April to May (Figs. 2b and 2c) indicates the development of the South Asian high.

In summary, the following climatological observations can be made. 1) The ridgelines of the subtropical anticyclone at various levels in the troposphere are continuous in the wintertime and exhibit a relatively zonal structure. The WEB tilts southward with increasing height, and the mean position of the WEB is closer to the equator; 2) In summer and in the Asian monsoon area, the ridgelines of the subtropical anticyclone in the middle and lower troposphere are discontinuous, but remain continuous in the upper troposphere. Furthermore, the WEB either tilts northward or is vertical, with the mean position of the WEB being located at $25-30^{\circ} \mathrm{N}$. The vertical tilt of the main body of the south Asian high is small, which suggests an equivalent barotropic structure; 3) Reversal of the meridional temperature gradient in the lower troposphere occurs in April along latitudes $10-20^{\circ} \mathrm{N}$ and within the longitudes $60-$ $110^{\circ} \mathrm{E}$; and 4) May is the period when the structure of the subtropical anticyclone varies most significantly.

\subsection{The break process of the WEB}

To examine the break process of the subtropical anticyclone belt in greater detail, pentad mean evolutions are analyzed (Fig. 3). In the third pentad of $\mathrm{April}^{2}$, the $850-\mathrm{hPa}$ ridgeline

2 Hereafter, the $n$th pentad of the $m$ th month will be referred to as the $n / m$ pentad. 

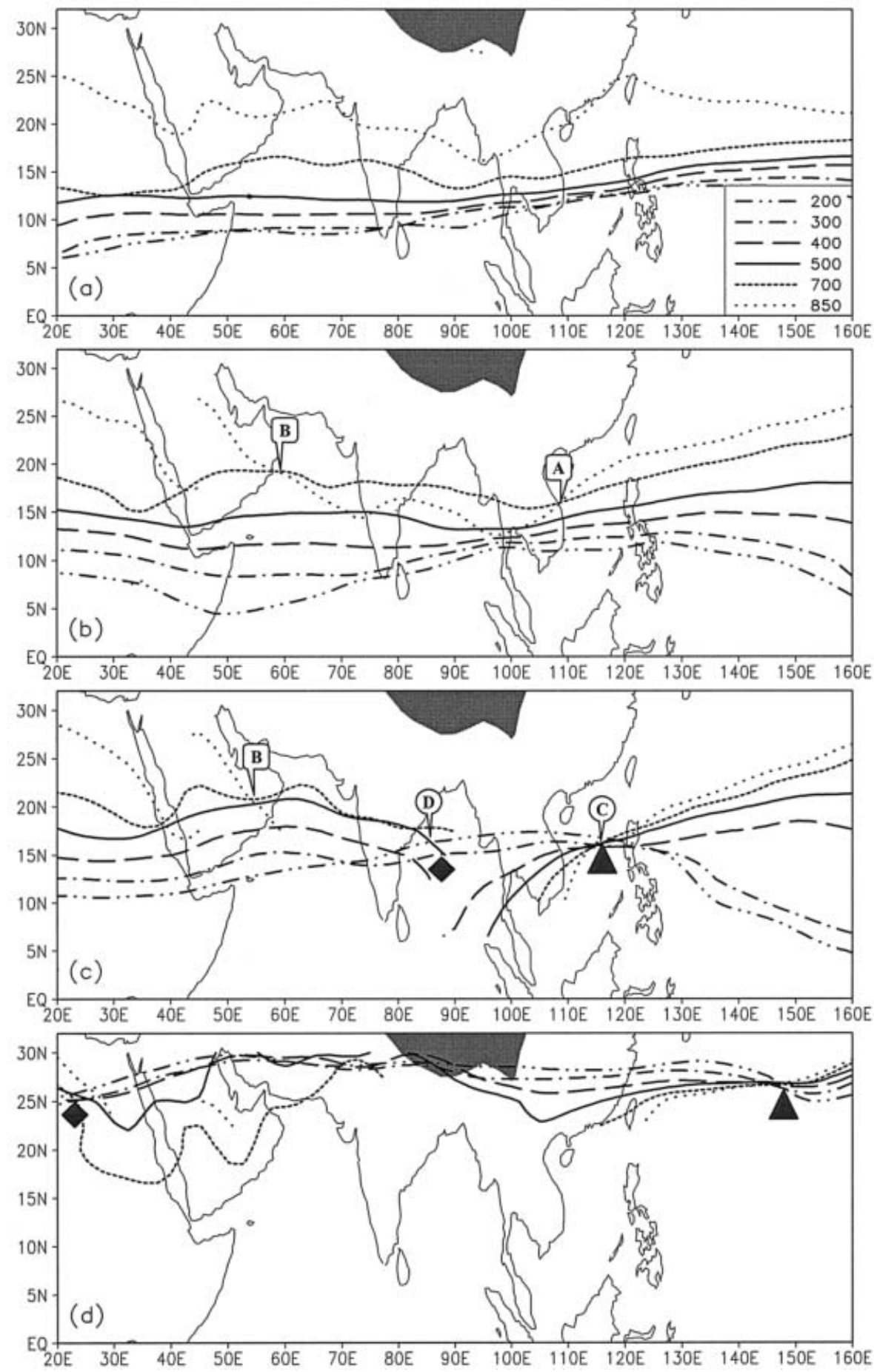

Fig. 2. The projections of the WEB in (a) January, (b) April, (c) May, and (d) July. The climatology is based on the period 1968-1996. Thick curves denote the subtropical anticyclone ridgelines on various isobaric surfaces (indicated by the numbers in legend). Shading indicates terrain above 3000 $\mathrm{m}$. The diamond and triangle indicate locations near which the meridional tilt of the WEB switches from southward to northward or vice versa. Details are discussed in the text. 

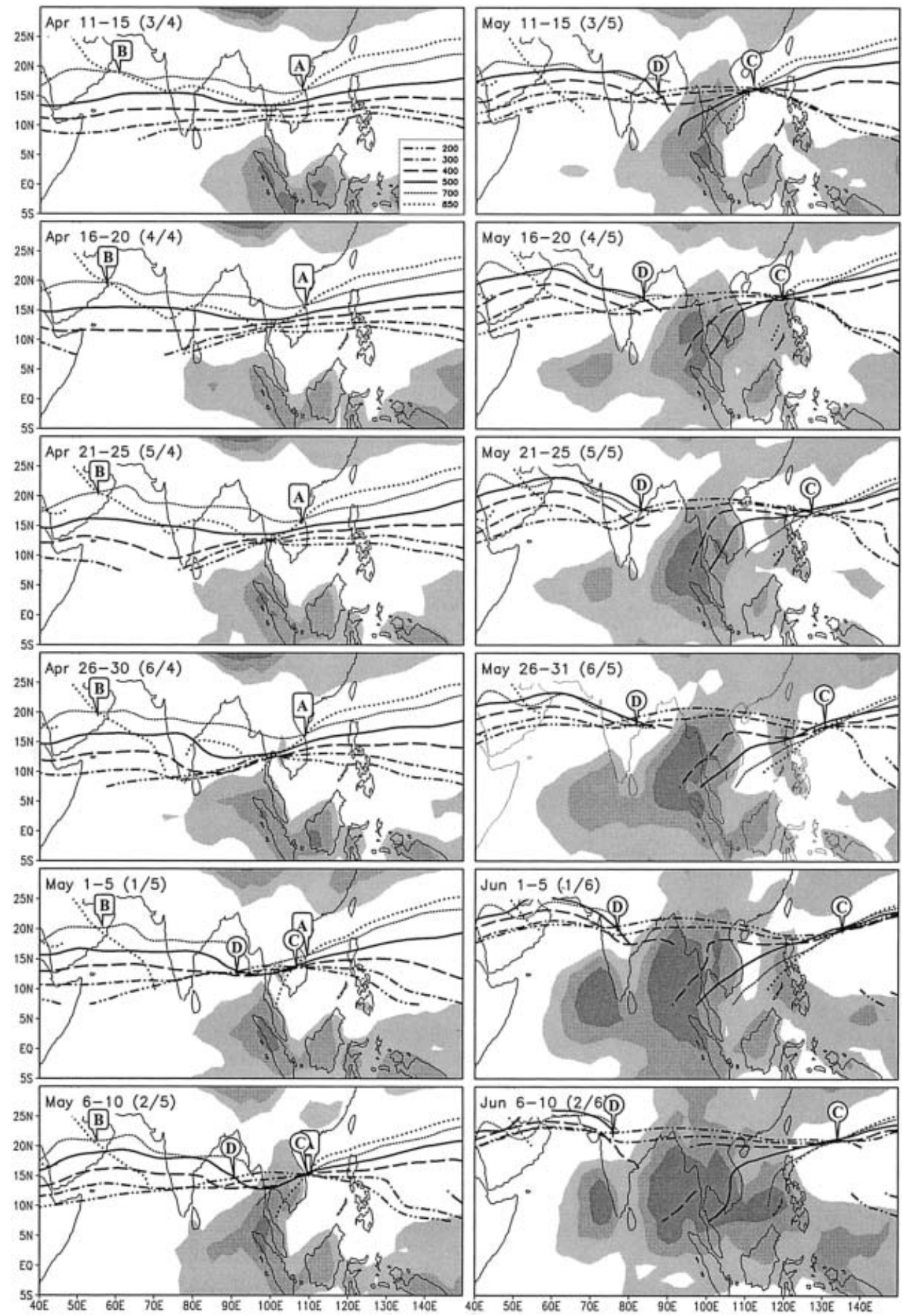

Fig. 3. The projections of the WEB and OLR $\left(\mathrm{W} \mathrm{m}^{-2}\right)$ from the third pentad of April to the second pentad of June. Thick curves denote the subtropical anticyclone ridgelines on various isobaric surfaces (indicated by the numbers in legend). Numbers in parenthesis in each panel represent pentad and month (the $n$th pentad of the $m$ th month). Shading indicates different OLR values in $\mathrm{W} \mathrm{m}^{-2}$ : light (between 230 and 215), heavy (between 215 and 200), and very heavy $(<200)$. 
intersects with that at $700 \mathrm{hPa}$ in the western SCS (point A) and northwestern Arabian Sea (Point B). Obviously, the switch of the WEB tilt between $\mathrm{A}$ and $\mathrm{B}$ below $700 \mathrm{hPa}$ takes place at least earlier than the $3 / 4$ pentad. Prior to the $1 /$ 5 pentad, active convection exists only south of $5^{\circ} \mathrm{N}$ and east of $80^{\circ} \mathrm{E}$. Significant changes in the upper troposphere start from the $5 / 4$ pentad, when the ridgelines above $500 \mathrm{hPa}$ are close together between $90-100^{\circ} \mathrm{E}$. By the $1 / 5$ pentad, two other intersection points (C and D) occur due to the northward (southward) migration of the upper (lower) ridgelines. At the same time, the $850-\mathrm{hPa}$ ridgeline completely splits into two segments over the BOB. Subsequently, the intersection point $\mathrm{C}$ (D) moves eastward (westward). The intersection points $\mathrm{C}$ and $\mathrm{D}$ thus represent the critical state at which the ridge axes in the upper troposphere $(200-500 \mathrm{hPa})$ are "vertical", and are identified as the crossing points between the $500-$ and $200-\mathrm{hPa}$ ridgelines.

By the $2 / 5$ pentad, point $\mathrm{C}$ reaches $108^{\circ} \mathrm{E}$ and almost overlaps with point $\mathrm{A}$, while point $\mathrm{D}$ remains around $90^{\circ} \mathrm{E}$. The $700-\mathrm{hPa}$ ridgeline is now split such that the tilt of the WEB is larger between $\mathrm{C}$ and $\mathrm{D}$. In this pentad, another important feature is that deep convection develops over eastern BOB and the Indochina Peninsula. The occurrence of convective activities indicates the onset of the Asian summer monsoon, which is consistent with the result reported by Zhang et al. (2002) that, based on the observed daily rainfall at 30 stations, the climatological monsoon onset date over the Indochina Peninsula is 9 May. Actually, the intersection points $\mathrm{C}$ and $\mathrm{D}$ are the STA discussed in section 3.1. Note also that at D the STA is not entirely vertical, while the ridgelines at $\mathrm{C}$ align almost completely vertical.

During the next (3/5) pentad, with the STA at point $\mathrm{C}$ migrating eastward and reaching $110^{\circ} \mathrm{E}$, the $500-\mathrm{hPa}$ ridgeline splits, and convective activities strengthen. The configuration of the subtropical anticyclone in the $4 / 5$ pentad is almost the same as that of the monthly mean pattern (see Fig. 2c). The $400-\mathrm{hPa}$ ridgeline is also broken, along with a significant southward displacement of the $500-\mathrm{hPa}$ ridgeline. The STA at Point $\mathrm{C}$ moves to the northeastern SCS, and the westernmost point of the $850-\mathrm{hPa}$ ridgeline abruptly retreats eastward to $120^{\circ} \mathrm{E}$.
At the same time, deep convection is active almost all over the SCS. These features reflect the onset of the SCSSM. When the STA at Point D moves westward, and reaches central and western India during the first two pentads of June, the south Asian summer monsoon onset occurs, accompanied by the occurrence of active convection over the southern Indian Peninsula and the eastern Arabian Sea.

It is obvious that the STA first establishes over the eastern BOB and Indochina Peninsula during the $1 / 5$ pentad. This change of the WEB tilt indicates that the switch from the winter to the summer monsoon starts here. When the WEB becomes perpendicular to the surface and then tilts northward, the MTG first vanishes and then becomes positive, which implies the replacement of the wintertime gradient by the summertime gradient. With the STA at points $\mathrm{C}$ and $\mathrm{D}$ moving northeastward and northwestward respectively, the summer subtropical high broadens its extent. It can be seen from Fig. 3 that deep convective activities mostly prevail between $\mathrm{C}$ and $\mathrm{D}$ from the $2 / 5$ pentad on. All these features clearly show that points $\mathrm{C}$ and $\mathrm{D}$ form the boundaries between the winter and summer types of the subtropical high. The onset of the Asian summer monsoon circulation is therefore closely associated with the location of the STA. The monsoon onset over the eastern $\mathrm{BOB}$ and the Indochina Peninsula (SCS) concurs with the break of the $850-$ and $700-\mathrm{hPa}$ (400-hPa) ridgelines.

\section{Relationship between the switch of the WEB tilt and the Asian summer monsoon onset}

In investigating the processes associated with the 1989 Asian summer monsoon, Wu and Zhang (1998) pointed out that the Asian summer monsoon onset that year consisted of three stages: the first was over the BOB, the second over the SCS, the third over India. They also suggested that thermal and mechanical forcing from the Tibetan Plateau contributed to an earlier monsoon onset over East Asia than that over South Asia.

The climatological characteristics of the Asian summer monsoon onset can be seen clearly from a time-longitude section of OLR and $850-\mathrm{hPa}$ winds along $10-15^{\circ} \mathrm{N}$ (Fig. 4). Deep convection (OLR $<230 \mathrm{~W} \mathrm{~m}^{-2}$ ) first ap- 


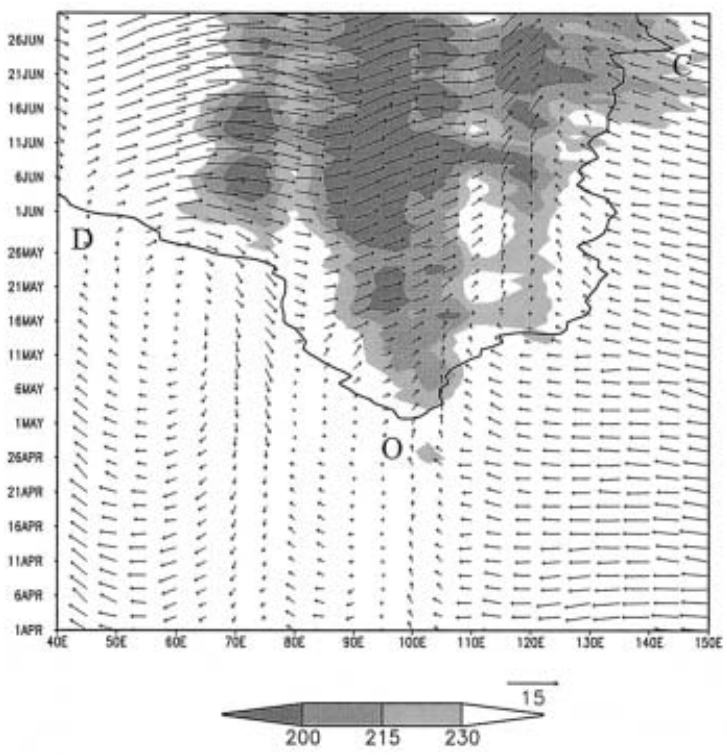

Fig. 4. Time-longitude cross section of the climatological OLR $\left(\mathrm{W} \mathrm{m}^{-2}\right)$ and 850-hPa winds ( $\mathrm{m} \mathrm{s}^{-1}$, vector) averaged within $10-15^{\circ} \mathrm{N}$. Shading indicates different OLR values in $\mathrm{W} \mathrm{m}^{-2}$ : Light (between 230 and 215), heavy (between 215 and 200), and very heavy $(<200)$. Thick solid curves OC and OD are the zero isolines of meridional mean upper tropospheric (200-500 hPa) temperature gradient in the vicinity of the WEB.

pears around $3-5$ May along $95-105^{\circ} \mathrm{E}$. In the convective region, southwesterlies or southerlies prevail, which indicates the summer monsoon onset over the eastern $\mathrm{BOB}$ and the Indochina Peninsula. Deep convection then occurs during 15-20 May over the SCS. The sudden eastward extension of the $230 \mathrm{~W} \mathrm{~m}^{-2}$ OLR isoline and southwesterlies illustrate the abruptness of the SCSSM onset. The third onset begins on 3 June over the western Indian Peninsula. A fourth onset starting from 15 June is over the western North Pacific, which corresponds to the beginning of the summer monsoon there (Wu and Wang 2000).

The longitudinal evolutions of the STA at points $\mathrm{C}$ and $\mathrm{D}$ in Fig. 3 are the thick solid lines OC and OD in Fig. 4, which represent the zero isoline of the mean upper tropospheric $(200-500 \mathrm{hPa})$ meridional temperature gradient (MTG) in the vicinity of the WEB, and are similar to that of the $230 \mathrm{~W} \mathrm{~m}^{-2}$ OLR isoline.
If this isoline is defined as the threshold for deep convection, strong ascending motion occurs only between OC and OD, except east of $130^{\circ} \mathrm{E}$. The curves OC and OD are also the boundaries of the region in which monsoon southwesterlies prevail. These results illustrate a close relationship between the establishment of the STA and the Asian summer monsoon onset.

Although Li and Yanai (1996) found that the reversal of the MTG, indicated by the difference of the mean upper tropospheric (200-500 hPa) temperature between $30^{\circ} \mathrm{N}$ and $5^{\circ} \mathrm{N}$, occurs first on the south side of the Tibetan Plateau (near $90-100^{\circ} \mathrm{E}$ ), the reversal time is at the end of May. This date is nearly one month later than what is found here. In other words, in determining the monsoon onset date, only the reversal of the MTG in the vicinity of the WEB should be considered since the low-level monsoon southwesterlies follow the switch of the WEB tilt or a break of the lower tropospheric ridgelines. This suggests that the switch of the WEB tilt is a result of the MTG change during the Asian summer monsoon onset. This conclusion is consistent with the result of Ueda and Yasunari (1998) that the warming phase over the Tibetan Plateau around mid-May is concurrent with the early onset of the Southeast Asian monsoon, and the thermal contrast between the Tibetan Plateau and the adjacent ocean is likely to induce the acceleration and eastward extension of the low-level monsoon flow, causing the abrupt commencement of the Southeast Asian monsoon, including the SCS monsoon.

\section{Identifying the SCS summer monsoon onset date based on the STA}

Figure 3 clearly shows that the STA is located over the northeastern SCS at the time of the monsoon onset (fourth pentad of May), which suggests that the SCSSM onset should be closely related to the STA. In this section the nature of the SCSSM onset is investigated in association with the switch of the WEB tilt, based on which the onset date could be determined.

\subsection{Climatological onset date}

The abruptness of the SCSSM onset can be seen in the large-scale atmospheric structure. 

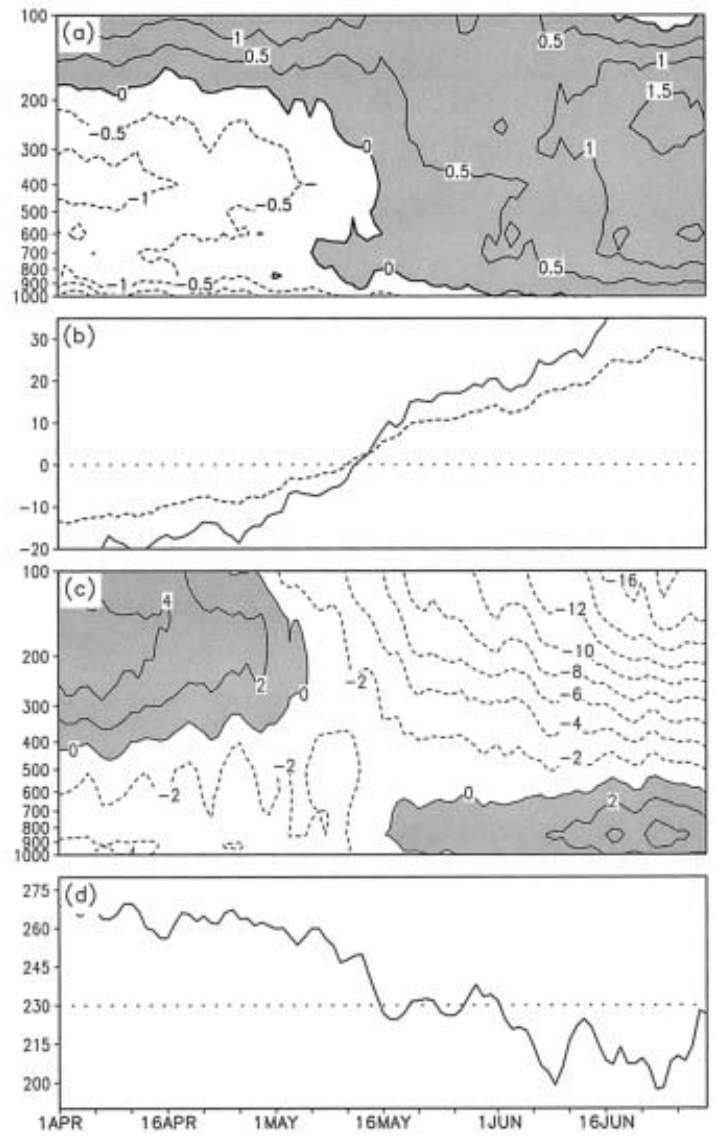

Fig. 5. (a) Pressure-time section of areaaveraged meridional temperature gradient $\left(10^{-3} \mathrm{~K} \mathrm{Km}^{-1}\right)$ over the SCS (5$20^{\circ} \mathrm{N}, 110-120^{\circ} \mathrm{E}$ ); (b) time series of the area-averaged zonal wind shear $\left(10^{-2} \mathrm{~m} \mathrm{~s}^{-1} \mathrm{hPa}^{-1}\right)$ over the SCS between 850 and $200 \mathrm{hPa}$ (dashed line) and between 500 and $200 \mathrm{hPa}$ (solid line); (c) Pressure-time section of area-averaged zonal wind $\left(\mathrm{m} \mathrm{s}^{-1}\right)$ over the SCS; and (d) time series of the area-averaged OLR $\left(\mathrm{W} \mathrm{m} \mathrm{m}^{-2}\right)$ over the SCS. Shaded areas indicate positive values.

First, an abrupt reversal of the sign in the MTG occurs throughout most of the troposphere around 16 May (Fig. 5a), which corresponds to the time of the establishment of the STA over the SCS (see Fig. 3). The contrast between the times before and after the onset is very distinct. The date around 16 May is also the time when the vertical zonal wind shear between 200 and
$500 \mathrm{hPa}$ changes its sign (Fig. 5b), which suggests that the wind and temperature fields in the vicinity of the WEB satisfy the thermal wind relationship, and demonstrates the validity of the theoretical discussion about the tilt of the WEB in section 2. Note also that the reversal of the MTG between $700 \mathrm{hPa}$ and $900 \mathrm{hPa}$ leads that in the upper layers by a few days, the time when the vertical shear between $200 \mathrm{hPa}$ and $850 \mathrm{hPa}$ zonal winds changes its sign is thus slightly earlier than 16 May (Fig. 5b). The evolutions of the zonal winds and convection also show similar changes. When westerlies begin to appear at the low levels on 16 May (Fig. 5c), the OLR value rapidly drops to below the critical value of $230 \mathrm{~W} \mathrm{~m}^{-2}$ (Fig. $5 \mathrm{~d}$ ). The significance of the MTG in the vicinity of the WEB to the SCSSM onset has been pointed out earlier by So and Chan (1997), who suggested that a north-south temperature gradient between South China and northern Australia might play an important role in the establishment of the summer monsoon over South China around Hong Kong.

It is obvious that the SCSSM onset date (16 May) as determined by the above four indices are fairly consistent in the climate mean. That is to say, these four elements reflect the main climatological characteristics of the SCSSM onset. In most of the previous studies, the 850$\mathrm{hPa}$ zonal wind and OLR are the two common indices for identifying the summer monsoon onset, especially for the SCSSM (e.g., Xie et al. 1998; Chan et al. 2000; He et al. 2001). In this paper, based on the above results, it is proposed that the area-averaged upper tropospheric $(200-500 \mathrm{hPa})$ MTG $\left(10-20^{\circ} \mathrm{N}, 110-\right.$ $120^{\circ} \mathrm{E}$ ) be used as a new index for identifying the SCSSM onset date. Although the areaaveraged zonal wind shear between $850 \mathrm{hPa}$ and $200 \mathrm{hPa}$ can also be chosen as an indicator, as has been used by Webster and Yang (1992) to estimate the summer monsoon intensity, the results in Fig. 5a and b suggest that its change is not as abrupt as the shear or MTG between $500 \mathrm{hPa}$ and $200 \mathrm{hPa}$ in assessing monsoon onset. After all, variations of the MTG reflect the essential features of monsoon circulation since the thermodynamic basis of the seasonal transition is the reversal of the MTG in the vicinity of the WEB, and the zonal wind shear depends on the variations of the MTG. 


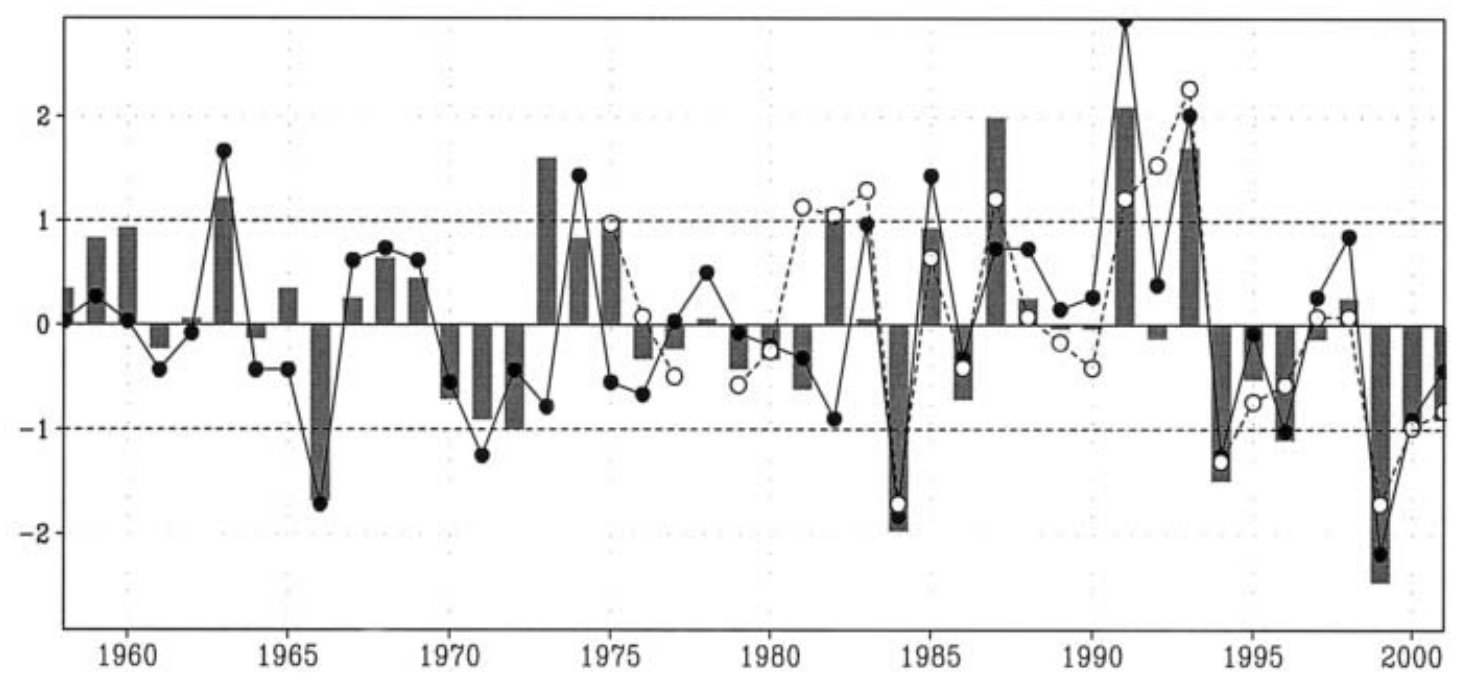

Fig. 6. Standardized (deviations from the mean divided by the standard deviation) SCSSM onset dates defined by the MTG (solid circles), U850 (bars) and OLR (open circles) for the period 19582001. A negative value corresponds to an early onset.

\subsection{Onset date for each individual year}

Based on the results of the previous subsection, the onset date for each individual year is defined as the day when the following criteria are first satisfied: 1 ) the area-averaged upper tropospheric (200-500 hPa) MTG over the SCS $\left(5-20^{\circ} \mathrm{N}, 110-120^{\circ} \mathrm{E}\right)$ changes from negative to positive; 2 ) the MTG remains positive for more than 6 days.

For comparison, an identical definition is applied to the $850 \mathrm{hPa}$ zonal wind (U850) and OLR, with the threshold of OLR chosen to be $230 \mathrm{~W} \mathrm{~m}^{-2}$. Of course, OLR data are only available from 1975 (except 1978).

It is found that in a large number of individual years, the dates determined by these three indices do not differ much (Table A1 in the Appendix), but in a few cases large differences of 10 to 26 days exist, e.g., 1965, 1973, 1975, 1982, 1983,1987 . It is also noteworthy that for most of the individual years, the dates derived from the MTG lead those from the other two indices. In other words, the onset of the lower tropospheric southwesterlies follows the switch of the WEB tilt. Results from the individual cases suggest that the switch of the WEB tilt appears to be the necessary but not sufficient condition responsible for the SCSSM onset. In a few cases such as the six years mentioned above, the WEB tilt had changed but the southwesterlies did not subsequently appear. A further examination of these six cases indicates that either the WEB was basically steep and its location was near $20^{\circ} \mathrm{N}$, the $850-\mathrm{hPa}$ ridgeline retreated to the northern SCS rather than out of the SCS, or the occurrence of convection was delayed. The question is what factors might have caused the switch of the WEB tilt to lead the occurrence of southwesterlies and convection by more than 10 days. Further investigations are obviously needed.

The mean onset dates as derived from MTG, U850 and OLR are 14 May, 17 May and 19 May, with standard deviations of 8.6, 10.3 and 12.3 days respectively. The standardized time series of the SCSSM onset date for each year shows a large interannual variability of the onset date, with the earliest differing from the latest by $\sim 1.5$ months (Fig. 6). The correlation coefficients among the time series of the onset dates all exceed the 99\% significance level (Table 1).

\section{Summary and discussion}

\subsection{Summary}

The variation in the structure of the subtropical anticyclone during seasonal transition from winter to summer, and its relation with the Asian monsoon onset, are investigated using the US National Centers for Environmental 
Table 1. Correlation coefficients between the SCS monsoon onset indices. See text for the definition of these indices.

\begin{tabular}{|l|l|l|l|}
\hline Index & MTG & U850 & OLR \\
\hline MTG & 1 & 0.870 & 0.706 \\
\hline U850 & & 1 & 0.829 \\
\hline OLR & & & 1 \\
\hline
\end{tabular}

Prediction/National Center for Atmospheric Research (NCEP/NCAR) reanalysis data from a new perspective. Diagnostic and theoretical analyses show that the line that separates westerlies to the north and easterlies to the south (the westerly-easterly boundary surface, WEB) well represents the three-dimensional structure of both the pressure and wind fields, and the tilt of the WEB is subject to the horizontal meridional temperature gradient in the vicinity of the WEB. Based on this concept, the climatological features associated with the Asian summer monsoon onset are examined in relation to the variation of the WEB tilt. Main findings of the present study are summarized as follows:

1) In the Asian monsoon area and in winter, the ridgelines of the subtropical anticyclone at various levels in the troposphere are continuous and exhibit a relatively zonal structure. The WEB tilts southward with increasing height and the mean position of the WEB is closer to the equator. In summer, the ridgelines of the subtropical anticyclone in the middle and lower (upper) troposphere are discontinuous (continuous) and the WEB either tilts northward or is vertical, with the mean position of the WEB being located at $25-30^{\circ} \mathrm{N}$. May is the period when the structure of the subtropical anticyclone varies most significantly.

2) During the seasonal transition, the tilt of the WEB changes from southward to northward. When the WEB becomes perpendicular to the surface or tilts northward, the meridional temperature gradient vanishes or becomes positive, implying the replacement of the winter monsoon by the summer monsoon. Defining the seasonal transition axis (STA) at the location where the WEB is vertical, it is found that the STA first occurs over eastern BOB and Indochina during the first pentad of May. The
STA is also the boundary between the winter and summer types of the subtropical high. The onset of the Asian summer monsoon circulation is therefore closely associated with the location of the STA. The monsoon onset over eastern BOB and the Indochina Peninsula (South China Sea) concurs with the break of the 850- and $700-\mathrm{hPa}(400-\mathrm{hPa})$ ridgelines. The migration of the STA, as well as evolutions of the OLR and the lower tropospheric wind fields, indicate that the establishment of the Asian summer monsoon consists of at least three stages in the climate mean, first over BOB and the Indochina Peninsula, then the South China Sea (SCS) and finally South Asia.

3) The SCS summer monsoon (SCSSM) onset exhibits a close relation to the STA. The climatological dates derived from four variables: the meridional mean temperature gradient near the WEB, zonal wind shear, zonal wind at low levels, and convection are mostly consistent. Considering that the thermodynamic basis of the seasonal transition is the reversal of the tropospheric temperature gradient in the vicinity of the WEB, the area-averaged meridional mean upper tropospheric $(200-500 \mathrm{hPa})$ temperature gradient in the vicinity of the WEB is suggested as an index for determining the SCSSM onset. The SCSSM onset date obtained using this index is compared with the onset dates determined by the area-averaged 850$\mathrm{hPa}$ zonal winds and OLR. The results show that in a large number of individual years, the dates determined by the three indices are consistent, which indicates that the initiation of the STA, or the reversal of the meridional temperature gradient, captures the essential feature associated with the SCSSM onset.

\subsection{Discussion}

This study introduced another index, the MTG, to define the onset of the Asian summer monsoon. An obvious question is why is yet another index necessary and why it is better than the others. Traditional definitions of the onset generally utilize rainfall, OLR, low-level winds or their combinations. However, all these at most characterize the two-dimensional evolution of the monsoon. On the other hand, the WEB and STA describe the three-dimensional changes circulation around the onset time so that differences and similarities, as well as 
linkages, among the different components of the Asia monsoon can be better understood. Furthermore, the STA can be used in practice as a guide to determine correctly the domain used for calculating the MTG in defining the onset.

In the boreal spring, temperature differences between the polar region and the equator gradually decrease with an increase in solar radiation. Differential heating of various spatial scales exists in the Asian monsoon region. In addition to the importance of planetary-scale thermal contrasts, the land-sea differential heating on the synoptic scale may help the earlier switch of the WEB tilt at lower levels. The results in this study show that the Asian summer monsoon onset depends to a great extent on the reversal of the meridional temperature gradient in the vicinity of the WEB in the middle and upper troposphere. The next step in this investigation is to identify what factors or processes that cause such a reversal. Of course, the Tibetan Plateau as an elevated heat source and its thermal contrast with the adjacent ocean are the important factors. The question is how they affect the temperature fields near the WEB. Statistically, in the long-term mean and in most of the individual years, the SCSSM onset date determined by the meridional temperature gradient slightly lead those by $850 \mathrm{hPa}$ zonal wind and OLR, which may imply the meridional temperature gradient to a certain extent has the potential for predicting the SCSSM onset. These questions should be further explored.

\section{Acknowledgments}

The NCEP/NCAR reanalysis data are provided by the NOAA-CIRES Climate Diagnostics Center, Boulder, Colorado, USA, from their Web site at http://www.cdc.noaa.gov/. This research is supported by the City University of Hong Kong Grant 7001212. Work of the first and third authors was supported partly by the Natural Science Foundation of China Grants 40135020 and 40375022 .

\section{Appendix}

Table A1. Dates of the SCS monsoon onset for each year (month-day)

\begin{tabular}{|c|c|c|c|}
\hline Year & MTG & U850 & OLR \\
\hline 1958 & $5-14$ & $5-21$ & \\
\hline 1959 & $5-16$ & $5-26$ & \\
\hline 1960 & $5-14$ & $5-27$ & \\
\hline 1961 & $5-10$ & $5-15$ & \\
\hline 1962 & $5-13$ & $5-18$ & \\
\hline 1963 & $5-28$ & $5-30$ & \\
\hline 1964 & $5-10$ & $5-16$ & \\
\hline 1965 & $5-10$ & $5-21$ & \\
\hline 1966 & $4-29$ & $4-30$ & \\
\hline 1967 & $5-19$ & $5-20$ & \\
\hline 1968 & $5-20$ & $5-24$ & \\
\hline 1969 & $5-19$ & 5-22 & \\
\hline 1970 & 5-09 & $5-10$ & \\
\hline 1971 & $5-03$ & $5-08$ & \\
\hline 1972 & $5-10$ & 5-07 & \\
\hline 1973 & $5-07$ & 6-03 & \\
\hline 1974 & $5-26$ & $5-26$ & \\
\hline 1975 & 5-09 & $5-28$ & $5-31$ \\
\hline 1976 & $5-08$ & 5-14 & $5-20$ \\
\hline 1977 & $5-14$ & $5-15$ & $5-13$ \\
\hline 1978 & $5-18$ & $5-18$ & \\
\hline 1979 & $5-13$ & $5-13$ & $5-12$ \\
\hline 1980 & $5-12$ & $5-14$ & $5-16$ \\
\hline 1981 & $5-11$ & $5-11$ & $6-02$ \\
\hline 1982 & 5-06 & 5-29 & 6-01 \\
\hline 1983 & $5-22$ & $5-18$ & $6-04$ \\
\hline 1984 & $4-28$ & $4-27$ & $4-28$ \\
\hline 1985 & $5-26$ & 5-27 & $5-27$ \\
\hline 1986 & $5-11$ & $5-10$ & $5-14$ \\
\hline 1987 & $5-20$ & 6-07 & 6-03 \\
\hline 1988 & $5-20$ & $5-20$ & $5-20$ \\
\hline 1989 & $5-15$ & $5-17$ & $5-16$ \\
\hline 1990 & $5-16$ & $5-17$ & $5-14$ \\
\hline
\end{tabular}




\begin{tabular}{|c|c|c|c|}
\hline Year & MTG & U850 & OLR \\
\hline 1991 & $6-08$ & $6-08$ & $6-03$ \\
\hline 1992 & $5-17$ & $5-16$ & $6-07$ \\
\hline 1993 & $5-31$ & $6-04$ & $6-16$ \\
\hline 1994 & $5-03$ & $5-02$ & $5-03$ \\
\hline 1995 & $5-13$ & $5-12$ & $5-10$ \\
\hline 1996 & $5-05$ & $5-06$ & $5-12$ \\
\hline 1997 & $5-16$ & $5-16$ & $5-20$ \\
\hline 1998 & $5-21$ & $5-20$ & $5-19$ \\
\hline 1999 & $4-25$ & $4-22$ & $4-28$ \\
\hline 2000 & $5-06$ & $5-07$ & $5-07$ \\
\hline 2001 & $5-10$ & $5-08$ & $5-09$ \\
\hline Mean & $5-14$ & $5-17$ & $5-19$ \\
\hline Standard & 8.6 & 10.3 & 12.3 \\
\hline Deviation (days) & & & \\
\hline
\end{tabular}

\section{References}

Chan, J.C.L., Y. Wang and J. Xu, 2000: Dynamic and thermodynamic characteristics associated with he onset of the 1998 South China Sea Summer monsoon. J. Meteor. Soc. Japan, 78, 367-380.

Chang, C.P. and G.T. Chen, 1995: Tropical circulations associated with southwest monsoon onset and westerly surges over the South China Sea. Mon. Wea. Rev., 123, 3254-3267.

Dai, N., A. Xie and Y. Zhang, 2000: Interannual and interdecadal variations of summer monsoon activities over the South China Sea. Climatic and Environmental Research, 5, 363-374 (in Chinese with English abstract).

Ding, Y. and Z. Liu, 2001: Onset and the evolution of the summer monsoon over the South China Sea during SCSMEX field experiment in 1998. J. Meteor. Soc. Japan, 79-1B, 255-276.

Fong, S.K. and A.Y. Wang, 2001: Climatological Atlas for the Asian Summer Monsoon. Macau Foundation, Macau, 318pp.

He, J., Y. Ding, H. Gao and H. Xu, 2001: Determination of the onset dates of the summer monsoon over the south China sea and monsoon indices. China Meteorological Press, Beijing, 123pp (in Chinese).

Hoskins, B.J., 1996: On the existence and strength of the summer subtropical anticyclones. Bull. Amer. Meteor Soc., 77, 1287-1292.

Hsu, H.H., C.T. Terng and C.T. Chen, 1999: Evolution of large scale circulation and heating dur-

ing the first transition of the Asian summer monsoon. J. Climate, 12, 793-810.

Kalnay, E., M. Kanamitsu, R. Kistler, W. Collins, D. Deaven, L. Gandin, M. Iredell, S. Saha, G. White, J. Wollen, Y. Zhu, M. Chelliah, W. Ebisuzaki, W. Higgins, J. Janowiak, K.C. Mo, C. Ropelewski, J. Wang, A. Leetmaa, R. Reynolds, R. Jenne and D. Joseph, 1996: The NCEP/ NCAR 40-year reanalysis project. Bull. Amer. Meteor. Soc., 77, 437-471.

Lau, K.M. and S. Yang, 1997: Climatology and Interannual variability of the Southeast Asian summer monsoon. Adv. Atmos. Sci., 14, 141162.

$\longrightarrow$, H.T. Wu and S. Yang, 1998: Hydrologic processes associated with the first transition of the Asian summer monsoon: A pilot satellite study. Bull. Amer. Meteor. Soc., 79, 1871-1882. , X. Li and M.T. Wu, 2002: Evolution of the large scale circulation, cloud structure and regional water cycle associated with the South China Sea monsoon during May-June, 1998. J. Meteor. Soc. Japan, 80, 1129-1147.

Li, C. and M. Yanai, 1996: The onset and interannual variability of the Asian summer monsoon in relation to land-sea thermal contrast. J. Climate, 9, 358-375.

Li, J.P. and J.F. Chou, 1998: The dynamics of the break of subtropical anticyclone beltGeostrophic effect. Chinese Science Bulletin, 43, 434-437 (in Chinese).

and Q.C. Zeng, 2000: Significance of the normalized seasonality of wind field and its rationality for characterizing the monsoon. Science in China (ser. D), 43, 646-653.

Liu, Y.M., G.X. Wu, H. Liu and P. Liu, 2001: Condensation heating of the Asian summer monsoon and the subtropical anticyclone in the Eastern Hemisphere. Clim. Dyn., 17, 327-338. , J.C.L. Chan, J.Y. Mao and G.X. Wu, 2002: The role of Bay of Bengal convection in the onset of the 1998 South China Sea summer monsoon. Mon. Wea. Rev., 130, 2731-2744.

Mao, J.Y., 2001: Variations in the configuration of the subtropical anticyclone during seasonal transition and mechanism of the Asian monsoon onset. Ph.D. Thesis, Institute of Atmospheric Physics, Chinese Academy of Sciences, Beijing, 139pp (in Chinese with English abstract).

, G.X. Wu and Y.M. Liu, 2002: Study on modal variation of the subtropical high and its mechanism during seasonal transition. Part I: Climatological features of subtropical high structure. Acta. Meteor. Sin., 60, 400-408 (in Chinese with English abstract).

Rodwell, M.R. and B.J. Hoskins, 2001: Subtropical 
anticyclones and summer monsoons. J. Climate, 14, 3192-3211.

So, C.H. and J.C.L. Chan, 1997: An observational study on the onset of the summer monsoon over South China around Hong Kong. J. Meteor. Soc. Japan, 75, 43-57.

Tao, S.Y. and L.X. Chen, 1987: A review of recent research on the East Asian summer monsoon in China. Monsoon Meteorology, C.P. Chang and T.N. Krishnamurti, Eds., Oxford University Press, 60-92.

Ueda, H. and T. Yasunari, 1998: Role of warming over the Tibetan Plateau in early onset of the summer monsoon over the Bay of Bengal and South China Sea. J. Meteor. Soc. Japan, 76, 112.

Webster, P.J., V.O. Magana, T.N. Palmer, J. Shukla, R.A. Tomas, M. Yanai and T. Yasunari, 1998: Monsoons: Processes, predictability, and prospects for prediction. J. Geophys. Res., 103, 14451-14510.

- and S. Yang, 1992: Monsoon and ENSO: Se- lectively interactive systems. Quart. J. Roy. Meteor. Soc., 118, 877-926.

Wu, G.X. and Y.S. Zhang, 1998: Tibetan Plateau forcing and the monsoon onset over South Asia and the South China Sea. Mon. Wea. Rev., 126, 913-927.

Wu, R. and B. Wang, 2000: Interannual variability of summer monsoon onset over the western North Pacific and the underlying process. $J$. Climate, 13, 2483-2501.

Xie, A., Y. Chung, X. Liu and Q. Ye, 1998: The interannual variations of the summer monsoon onset over the South China Sea. Theor. Appl. Climatol., 59, 201-213.

$\mathrm{Xu}$, J. and J.C.L. Chan, 2001: First transition of the Asian summer monsoon in 1998 and the effect of the Tibet-tropical ocean thermal contrast. J. Meteor. Soc. Japan, 79, 241-253.

Zhang, Y.S., T. Li, B. Wang and G.X. Wu, 2002: Onset of the summer monsoon over the Indochina Peninsula: Climatology and interannual variations. J. Climate, 15, 3206-3221. 